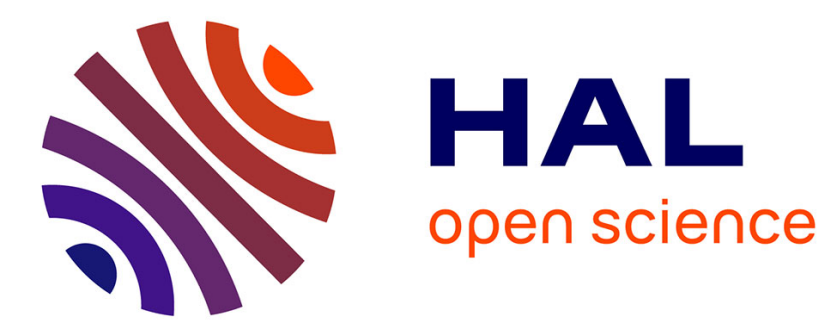

\title{
The Determinants of Domestic and Cross Border Bank Contagion Risk in South East Asia
}

Carlos Bautista, Philippe Rous, Amine Tarazi

\section{To cite this version:}

Carlos Bautista, Philippe Rous, Amine Tarazi. The Determinants of Domestic and Cross Border Bank Contagion Risk in South East Asia. 2007. hal-00918555

\section{HAL Id: hal-00918555 \\ https://hal-unilim.archives-ouvertes.fr/hal-00918555}

Preprint submitted on 13 Dec 2013

HAL is a multi-disciplinary open access archive for the deposit and dissemination of scientific research documents, whether they are published or not. The documents may come from teaching and research institutions in France or abroad, or from public or private research centers.
L'archive ouverte pluridisciplinaire HAL, est destinée au dépôt et à la diffusion de documents scientifiques de niveau recherche, publiés ou non, émanant des établissements d'enseignement et de recherche français ou étrangers, des laboratoires publics ou privés. 


\title{
The determinants of domestic and cross border bank contagion risk in Southeast Asia ${ }^{*}$
}

\author{
Carlos Bautista, Philippe Rous and Amine Tarazi ${ }^{* *}$
}

\begin{abstract}
This paper addresses the issue of both domestic and cross border systemic risk for 8 countries in Southeast Asia (Hong Kong, Indonesia, Korea, Malaysia, The Philippines, Singapore, Taiwan and Thailand). We use weekly data on individual bank stock prices from 2000 to 2005 to construct bank contagion measures based on the exponential weighted average correlations of the residuals of the market model. Our results show that average pair-wise correlations significantly differ among countries and that the probability that a specific shock extends to other banks is better predicted by asset risk indicators and market based risk measures, such as systematic risk, for cross country contagion. In contrast, for domestic contagion, liquidity risk indicators and bank opaqueness proxies perform better. Our findings suggest that whereas illiquidity, but not insolvency, is a major concern at the domestic level the opposite result holds for cross country contagion.
\end{abstract}

Keywords: Bank contagion, systemic risk, Southeast Asia.

JEL classification: G21, G29

Correspondence:

\author{
Carlos C. Bautista \\ College of Business Administration \\ University of the Philippines \\ Diliman, Quezon City 1101, Philippines

\section{Philippe Rous} \\ Laboratoire d'Analyse et de Prospective \\ Économiques, Université de Limoges \\ 5, rue Félix Eboué B.P. 3127 \\ 87031 Limoges Cedex 1 - France \\ Amine Tarazi** \\ Laboratoire d'Analyse et de Prospective \\ Économiques, Université de Limoges \\ 5, rue Félix Eboué B.P. 3127 \\ 87031 Limoges Cedex 1 - France
}

$\begin{array}{ll}\text { Tel } & +6329284571 \\ \text { Fax } & +6329207990 \\ \text { E-mail } & \text { bautista@up.edu.ph } \\ \text { Web } & \text { www.upd.edu.ph/ cba/bautista } \\ & \\ \text { Tel } & +33555149213 \\ \text { Fax } & +33555149001 \\ \text { E-mail } & \text { rous@unilim.fr } \\ \text { Web } & \text { www.fdse.unilim.fr } \\ & \\ \text { Tel } & \text { +33555149213 } \\ \text { Fax } & \text { +335551490 01 } \\ \text { E-mail } & \text { amine.tarazi@unilim.fr } \\ \text { Web } & \text { www.fdse.unilim.fr }\end{array}$

\footnotetext{
* This paper was prepared for the ASIA-LINK human resource development project: Euro-Philippines Network on Banking and Finance, Safety and Soundness of the Financial System, coordinated by the University of Limoges (www.upd.edu.ph/ cba/asialink). ASIA-LINK is a Programme of the European Commission that seeks to promote regional and multilateral networking among higher education institutions in Europe and developing economies in Asia.

${ }^{* *}$ Corresponding author.
} 


\section{The determinants of domestic and cross border bank contagion risk in Southeast Asia}

\section{Introduction}

The 1997 Asian financial crisis episode exposed the structural weaknesses of several East Asian economies. Structural reforms were initiated as soon as the effects of the crisis subsided to strengthen institutions that failed to protect the economy from the undesirable effects of the crisis. Crucial to these economies are their banking institutions which were at the forefront of the crisis. Attempts to correct these structural weaknesses especially in the banking sector of East Asian economies are currently being implemented especially in the area of bank regulation and supervision. It is hoped that with these changes, their economies are better prepared should similar systemic shocks hit the region in this post-crisis period.

Prior to the Mexican and the Asian crises, structural adjustment problems in one economy remained within its borders and no one ever thought that contagion was a possibility and that it can occur with surprising speed. Immediately after the Asian crisis episode, the literature on systemic risk and contagion grew at a rapid pace as researchers and analysts scrambled to explain the nature of the events that lead to the massive system breakdown. Close to a decade has past and a large literature on the Asian crisis has deepened the understanding of the causes of the crisis and how it was propagated (See for example, Kaminsky and Reinhart (2000)). All the more in an increasingly integrated world, these studies have alerted policymakers that a crisis in one economy can be contagious. Thus, in the post-crisis era, the threat of systemic risk both at the regional level and within borders remains, if it has not increased. An area of research on contagion that has not been fully explored is concerned with systemic risk at the banking sector level in Asia. While banking sector systemic risk analysis is flourishing in advanced economies (See De Nicolo and Kwast (2002) or Demirgüç-Kunt et al (2006, forthcoming) and their 
references), there are only a few studies on bank domestic contagion for the Asian region (See for example, Bystrom, (2004)).

This paper's task is to examine in detail, systemic risk in the banking sector of East Asia. In this study, the magnitude of banking sector systemic risk in each country is measured by the average correlation of bank equity returns, adjusted for market return movements (individual firm specific risk) using various techniques. ${ }^{1}$

We focus on both domestic measures of potential systemic risk but also on cross-border indicators. Because our aim is to focus on the post-crisis period we consider the period 2000-2005. Further, we build a framework to assess the link between individual bank correlations and systemic (domestic or cross border) risk. To complete the analysis, the study attempts to explore the determinants of significant individual correlations using a large set of firm specific variables based on both accounting and market data.

The paper is organized as follows. The second section briefly reviews the literature on systemic risk and discusses the issue as regards Southeast Asia. The third section outlines the method used by the study. The fourth section describes the data set and discusses the empirical results. The final section gives the conclusion.

\section{Systemic risks in the East Asian region}

Because of the complexity of the problem arising from systemic events, a variety of explanations have been put forth in an abundant literature. This can be gleaned from De Bandt and Hartmann (2000) who have conducted an extensive survey of systemic risk in general,

\footnotetext{
1 The dynamic conditional correlation model (DCC) of Engle (2002) and the rolling exponential weighted average correlations were the methods used in the estimation of the correlations. However because of computing constraints (missing observations for some banks in our sample and therefore incomplete series for DCC computations) and since the estimated correlations did not differ in terms of closeness to each other, the latter was chosen over the former.
} 
covering both theory and empirical work. ${ }^{2}$ Accordingly, systemic risk can be defined broadly or narrowly, depending on whether it is the result of single (second round effects of shocks affect only one entity) or wide (second round effects of shocks affect many entities) systemic events. Systemic risk arises when systemic events of either kind adversely affect a large number of institutions and prevent the financial system from performing normally.

The analysis of systemic risk in the empirical literature is conducted in several ways. For example, Schoenmaker (1996) makes use of autoregressive poisson regression on U.S. bank failure count data against macroeconomic variables and finds evidence of bank contagion. Worthington and Higgs (2004) use a multivariate GARCH model of the BEKK type and finds volatility spillovers in stock markets among some East Asian economies. Gropp and Vesala (2005) and Gropp and Moermann (2004), using a sample of European banks, have successfully used extreme value theory in isolating contagion in market data.

The most popular method, especially in the analysis of the Asian crisis, is to measure contagion effects of an event affecting one or more entity on other entities. This may be done through correlation analysis - the method chosen by the present study - of either the equity returns or the exchange rates. One of the first articles on Asian crisis contagion is by Baig and Goldfajn (1998) who show elevated levels of exchange rate correlation during the crisis period. They take this as an indicator of contagion. A particularly influential paper on contagion during the Asian crisis is by Forbes and Rigobon (2002) who showed that with appropriate adjustments to account for the increase in the volatility of variables during abnormal times, contagion cannot be detected and what is apparent is the usual interdependence of variables that are also present during normal periods. Recently, Corsetti et al (2005) showed that Forbes and Rigobon's tests for contagion are too restrictive and lead to a bias for the hypothesis of no contagion. They suggest

\footnotetext{
2One could notice that their work largely describes the extensive literature on bank systemic risk in Europe
} 
caution in taking increased correlation as an indicator of contagion and propose to test contagion using correlations that have accounted for the influence of the data generating process from a simple factor model.

Attempts to explain the causes of the Asian crisis contagion itself have also been accomplished by researchers. It has been noted that prior to the crisis, the less developed economies embarked in financial and trade liberalization programs almost simultaneously in the early 1990s. Typically, these economies with wide savings investment gaps presented opportunities for investment in emerging market equities and encouraged cross border activities of developed country banks. The explanation of contagion hinges heavily on the notion of a common lender country. This in fact lead to the 'twin crisis' sub-literature that attempts to disentangle the currency crisis from the banking crisis. Kaminsky and Reinhart (2000) provide details on the common bank creditor as one of the transmission channels leading to the crisis aside from trade links and other liquidity channels. Sbracia and Zaghini $(2001,2003)$ expound on the role of both domestic and foreign banks in a country in the transmission of shocks during the Asian crisis. Complementing the results of Kaminsky and Reinhart, they list the stylized facts on the common lender channel that reflected a high degree of vulnerability of these economies. They then construct a vulnerability index for emerging market economies based on the common lender channel.

It is clear from some papers that in the aftermath of the crisis, interest in the East Asian region is coming back. Hohl et al (2005) document the increase in cross border banking activity in Asia and warn anew of the dangers of systemic events, especially in light of reforms undertaken since the crisis of 1997. They describe how the Basel 2 framework can help address systemic risk in this regard. From this short review, it is clear that an analysis of systemic risk in Western banking (Europe and US) should be different from that of Asian banking sectors. There are a number of reasons for this. First, Western banks are quite sophisticated and mature enough such that their 
role of translating savings to productive investments are well defined. Emerging market banks play the same role but more importantly, because of the wide savings - investment gap, it makes them ideal channels of foreign funds to fill in this gap. Thus while cross border banking activity in Europe is increasing because of more integration among national banks (primarily because savings-investment channels are being integrated across countries), cross border activity in the Asian region has more to do with the infusion of scarce funds to supplement domestic resources. Such cross border activities involves both foreign and domestic banks. ${ }^{3}$ As domestic banks mature and grow into sophistication in the post crisis period, the dangers of domestic systemic risk will surely rise aside from cross border systemic risk arising from common lender channels.

\section{Method}

In this paper, systemic risk potential is measured by correlations of stock returns which have proven to be suitable indicators in previous studies (De Nicolo and Kwast (2002)). We retain this type of approach because alternative measures based either on abnormal returns or on the correlations of Merton based distance to defaults are unable to reveal episodes of systemic risk during the post crisis period that we analyse (2000-2005) $)^{4}$

To control for market movements and country specific factors we focus on the correlations of the residuals of a market model rather than on the correlations of the stock returns. Cross correlations between each pair of banks operating in the same country and cross correlations between each pair of banks operating in different countries are used to compute both domestic

\footnotetext{
${ }^{3}$ One would suspect that the introduction of a common currency, the Euro, hastened this integration and growing interdependence among these European banks.

${ }^{4}$ As a preliminary step we considered negative abnormal returns by estimating market models on moving estimation windows. A very low number of banks exhibit abnormal returns simultaneously (within a one week window) showing that unexpected shocks do not generally affect banks as a group (cluster effects). We also computed correlations on the basis of distance to defaults (Merton model) which exhibit relatively high and mostly stable values because of very low changes in individual default risks during the period 2000-2005. These results are available from the authors on request.
} 
average correlations and cross-border ${ }^{5}$ average correlations. Correlations are estimated using exponential weighted average rolling correlations. The estimated average correlations are tested for their significance. We also compute a measure of the statistical contribution of each bank to average domestic country correlation or average cross border country correlation by regressing each average individual correlation time series on the average corresponding country correlation and test for significance. Next, significant contributions are introduced in a binary probit model to capture the determinants of systemic risk potential using a large set of accounting based and market based variables.

\subsection{Measuring domestic and cross border potential systemic risk}

Formally, let $i(P)$ represent bank $i$ of country $P$ and $R_{i(P) t}$ the weekly stock return of this bank. The market adjusted return $r_{i(P) t}$ is the residual at time $t$ of equation 1 :

$$
R_{i(P) t}=\alpha_{i}+\beta_{i} R M_{P t}+r_{i(P) t}
$$

estimated on the rolling one year window $[t-51, t]$ and where $R M_{P t}$ is the weekly market return for country P. Alternatively, we compute market adjusted returns using other specifications (e.g., residuals from a constant return model, from a two-index market model including the banking sector index, from a two-index GARCH model and standardised residuals from a two-index GARCH model). For simplicity, and because our aim is to focus on the determinants of comovements of returns rather than on their statistical properties we opted to use the standard single-index market model in the rest of our investigation. Nevertheless, we check that the residuals computed with the different methods have a similar profile except when they are standardised in which case they are much lower.

\footnotetext{
5 The cross border systemic risk that is considered here refers to risk arising from co-movements of Asian bank equity prices and not due to cross border activities referred to in the review in Section 2 which refer to foreign, i.e., non-Asian banks' activities in the region.
} 
Denoting $\rho_{t}(i, j)$ as the moving exponentially weighted correlation evaluated at time $t$ between $r_{i t}$ and $r_{j t}{ }^{6}$ the domestic mean correlation within country $P, D O M C_{P t}$, at time $t$ is calculated as:

$$
D O M C_{P t}=\frac{1}{N_{P t}} \sum_{i \in P} \sum_{j \in P} \rho_{t}[i(P), j(P)] \quad ; \quad i \neq j
$$

where $N_{P t}$ is the number of (non redundant) domestic pair-wise correlations, at time $t$, within country $P$. Because we are concerned with how negative shocks affecting one bank might spread to other banks and not with the implications of positive shocks (unexpected increase in stock prices) we also compute correlations between simultaneously negative residuals solely. We further look at the correlations of sharp decreases in returns considering several thresholds $(-3 \%$ and $-10 \%)$. The series of domestic mean correlations that can be computed with these different definitions are highly correlated. We therefore retain the standard definition involving all the residuals (positive and negative). Another issue that arises when computing correlations is that higher volatility on the market is often associated to higher correlation (Forbes and Rigobon (2002)). To check that our measures are not sensitive to changes in market volatility we also compute volatility adjusted correlations that account for varying volatility in the series of returns ${ }^{7}$. Both methods yield very close results and we therefore focus in the rest of the study on the standard correlation measure that is adjusted for changes in market volatility.

${ }^{6} \rho_{t}(i, j)=\sum_{s=0}^{51} \lambda^{s} r_{i(P) t-s} r_{j(P) t-s} / \sqrt{\left(\sum_{s=0}^{51} \lambda^{s} r_{i(P) t-s}^{2}\right)\left(\sum_{s=0}^{51} \lambda^{s} r_{j(P) t-s}^{2}\right)}$ where $\lambda=0.940$ as suggested in Engle [2002].

7 Volatility adjusted correlation at time $t, \rho_{\mathrm{ijt},}^{*}$ as suggested by Forbes and Rigobon (1999), is calculated as : $\rho_{i j t}^{*}=\frac{\rho_{i j t}}{\sqrt{1+\delta\left(1-\rho_{i j t}{ }^{2}\right)}}$ where $\delta=0.5\left(\frac{\sigma_{i t}^{2}}{\overline{\sigma_{i}^{2}}}+\frac{\sigma_{j t}^{2}}{\overline{\sigma_{j}^{2}}}\right), \sigma_{i t}{ }^{2}$ is the variance of returns $\mathrm{r}_{\mathrm{it}}$ evaluated on the sample $[\mathrm{t}-52, \mathrm{t}]$ and $\overline{\sigma_{i}^{2}}$ is the whole sample $[1994,2005]$ variance of $\mathrm{r}_{\mathrm{it}}$. 
Similarly, because our aim is to focus on market adjusted return co-movements for banks operating in different countries, we also calculate the cross border mean correlations, $C B M C_{P t}$ involving each bank $i$ of country $P$ with any other bank $j$ of other countries $P^{\prime},\left(P^{\prime} \neq P\right)$ :

$$
C B M C_{P_{t}}=\frac{1}{N^{\prime} P_{t}} \sum_{P \neq P} \sum_{i \in P} \sum_{j \in P^{\prime}} \rho_{t}\left[i(P), j\left(P^{\prime}\right)\right]
$$

where $N_{P t}^{\prime}$ is the number of cross border (non redundant) correlations for country $P$ at time $t$.

We then test for the null of no domestic (respectively cross border) correlation for each country through the statistic:

$$
T D O_{P t}=\frac{D O M C_{P t} \sqrt{N_{P t}}}{D O S C_{P t}}
$$

where $D_{O S C}$ is the standard deviation of domestic correlations: ${ }^{8}$

$$
\operatorname{DOSC}_{P t}=\sqrt{\frac{1}{N_{P t}} \sum_{i \in P} \sum_{j \in P}\left\{\rho_{t}[i(P), j(P)]-D O M C_{P t}\right\}^{2}} \quad ; \quad i \neq j
$$

The individual mean domestic $\left(D O M C_{i(P) t}\right)$ and cross border $\left(C B M C_{i(P) t}\right)$ correlations for bank $i(P)$ are evaluated at time $t$ as:

$$
\text { (6) } \quad \operatorname{DOMC}_{i(P) t}=\frac{1}{N_{i(P) t}} \sum_{j \in P} \rho_{t}[i(P), j(P)] ; \quad C B M C_{i(P) t}=\frac{1}{N_{i(P) t}^{\prime}} \sum_{P^{\prime} \neq P} \sum_{j \in P^{\prime}} \rho_{t}\left[i(P), j\left(P^{\prime}\right)\right]
$$

where $N_{i(P) t}\left(\right.$ resp. $\left.N_{i(P) t}^{\prime}\right)$ stands for the number of domestic (respectively cross border) correlations involving bank $i(P)$ at time $t$.

8 Similarly, we define a statistic $T C B_{P t}$ for the null of no cross border correlation for country $P$ :

$T C B_{P t}=\frac{C B M C_{P t} \sqrt{N_{P t}^{\prime}}}{C B S C_{P t}}$ where $C B S C_{P t}=\sqrt{\frac{1}{N_{P t}^{\prime}} \sum_{P \prime} \sum_{i \in P} \sum_{j \in P}\left\{\rho_{t}\left[i(P), j\left(P^{\prime}\right)\right]-C B M C_{P t}\right\}^{2}}$ 


\subsection{Statistical contribution of individual banks to country systemic risk}

We assess the statistical contribution of a given bank $i(P)$ to its country $P$ domestic systemic risk by regressing each individual mean correlation involving bank $i(P)$ on country $P$ average domestic correlation:

$$
\mathrm{DOMC}_{i(P) t}=\alpha_{i}+\lambda_{i} \mathrm{DOMC}_{P t}+\varepsilon_{i t}
$$

Equation (7) is estimated only for sub-periods where the country average correlation $D O M C_{P t}$ is positive and significant. ${ }^{9}$ The statistical contribution of each bank to domestic systemic risk is, in this setting, given by the value and significance of the $\lambda_{i}$ coefficient. In this sense when, for a given bank the value of $\lambda_{i}$ is significantly greater than 1 , we take this to mean that the bank overreacts in terms of co-movements of its stock price with other banks' stock prices and therefore in terms of contagion. In such a case, a bank's individual mean correlation is significantly higher than the country mean correlation.

Similarly, we measure the contribution of bank $i(P)$ to cross border correlation of country $P$ using the same method but by regressing individual bank cross border correlations $C B M C_{i(P)}$ on country $P$ average cross border correlation $C B M C_{P t}$ :

$$
\mathrm{CBMC}_{i(P) t}=\alpha_{t}{ }^{\prime}+\lambda_{l}{ }^{\prime} \mathrm{CBMC} \mathrm{C}_{P t}+\varepsilon_{i t}
$$

where the actual contribution or sensitivity of each bank is given by the value and significance of the $\lambda_{i}^{\prime}$ coefficient.

\subsection{Econometric specification}

Our aim is to investigate, within our sample of banks and countries, which type of banks are the most likely either to trigger systemic risk or to sharply react to events affecting other banks. Under the contagion hypothesis a higher share of interbank activities in the balance sheet is

${ }^{9}$ We required $T D O_{P t}$ and $T C B_{P t}$ to be greater than 2. 
assumed to increase the probability that a bank becomes illiquid and in turn spreads illiquidity among other banks in the industry. However, under the too-big-to-fail hypothesis this is less likely to happen to large banks which would immediately receive support from monetary and supervisory authorities. Under the asymmetric information hypothesis market participants are unable to discriminate among solvent and insolvent banks and particularly those with a high share of non-tradable and opaque loans in total assets. Such banks would therefore be more likely to suffer from a widespread panic within the banking industry. In order to investigate these hypotheses we build a multivariate regression framework based on the systemic risk potential measures and the individual contributions to average residual correlations we previously estimated.

\subsubsection{Dependent variable}

In our setting, domestic (respectively cross border) contribution of bank $i$ to systemic risk is assumed to play a prominent role if $\lambda_{i}$ (respectively, $\left.\lambda_{i}^{\prime}\right)$ is greater than 1 . In this sense the correlations (co-movements) of market adjusted stock returns of a given bank with those of other banks are on average higher than the mean correlation. Therefore on the basis of the estimated values and standard deviations of these coefficients $\lambda_{i}$ and $\lambda_{i}^{\prime}$, we define two binary variables DP_DOM_ $2_{\mathrm{i}}$ and DP_CB_2 $2_{\mathrm{i}}$ such that DP_DOM_ $2_{\mathrm{i}}\left(\right.$ respectively $\left.\mathrm{DP} \_\mathrm{CB} \_2_{\mathrm{i}}\right)$ equals 1 if we can reject the null " $\lambda_{i} \leq 1$ " (respectively " $\lambda_{i}^{\prime} \leq 1 "$ ) at the $2 \%$ level and 0 otherwise.

Alternatively, we also consider for the dependent variable the values taken by individual bank mean correlations, i.e., for each bank either the domestic mean correlation with every other domestic bank or the cross border mean correlation with every bank from other countries. Such an approach is much less constraining and allows to capture the determinants of bank stock comovements without imposing a criterion to discriminate sharp and moderate stock price reactions. 


\subsubsection{Independent variables}

To explain the probability of a relatively sharp reaction of bank $i(P)$ with respect to the mean (domestic or cross border) correlation of country $\mathrm{P}$ we regress each of these two binary variables on a large set of accounting variables, capturing the size and the structure of bank balance sheets as well as bank risk and performance. We also consider market based risk indicators that are commonly used in the literature (see Table 1). The values taken by each variable are the mean values computed over the whole sample period.

Table 1 here

\subsubsection{Model specification}

As a first step, we consider the predictive power of each indicator by running probit regressions in which we introduce each explanatory variable separately. Then, on the basis of the results of this first step, within each category (size, capital adequacy, earnings, liquidity, etc.) we isolate the most significant variables (5\% level). As a second step, we identify, within this restricted set of variables, the optimal set of explanatory variables by selecting them through a stepwise procedure. ${ }^{10}$ We check for possible collinearity among the independent variables by running a Farrar - Glauber test for the null of no collinearity. When required, to deal with collinearity, we introduce an additional constraint of quasi-orthogonality ${ }^{11}$ in the stepwise process. As a third step, we test for the stability of this optimal set of explanatory variables with regard to several factors such as bank type, its nationality, its domestic and world rankings. For

\footnotetext{
${ }_{10} \mathrm{P}$-values for introduction and rejection are 5\%. To avoid estimating the model on an excessively small sample (because very few observations are available for some variables), we require that the introduction of an additional variable does not induce (1) an estimation sample with a size less than half of the potential sample size and (2) a loss of "Y=1" instances exceeding 50\%.

11 This constraint allows us to exclude a variable if its introduction would induce a rejection of the null (no collinearity) with a p-value less than $50 \%$.
} 
this purpose, we introduce additional dummy variables in the estimations to test for the stability of the equation. ${ }^{12}$ These dummy variables are presented in Table 2.

Table 2 here

\section{$4 \quad$ Data set and Results}

\subsection{Data and independent variable definitions}

For the purpose of our study which comprises 8 East Asian countries (Hong Kong (HK), Indonesia (ID), Korea (KO), Malaysia (MY), The Philippines (PH), Singapore (SG), Taiwan (TW) and Thailand $(\mathrm{TH})$ ), we use weekly stock prices that come from Datastream International and annual accounting data (balance sheet and income statement) that are extracted from Bankscope for the period 2000-2005.13 The values of the different regressors (prefixed with M6_) are averages from the whole sample period 2000 - 2005. To ensure that we use a clean sample, banks with non actively traded stocks (two subsequent identical quotes for, at least, $50 \%$ of the whole quotation sample) are omitted and to avoid the effects of outliers on the results, we eliminate extreme observations in each regressor that induce a variation coefficient (standard deviation/sample mean) greater than two. With these restrictions our sample is limited to 125 banks (See column 1 of Table 4). Descriptive statistics of accounting ratios and market based risk and default risk indicators are given in Table 3.

Table 3 here

\footnotetext{
12 Assuming that the estimated model is (1) $\operatorname{Prob}\left\{Y_{i}=1\right\}=\Phi\left(\beta_{1}+\beta_{2} X_{2 \mathrm{i}}+\ldots+\beta_{\mathrm{k}} X_{k i}\right)$, we test for stability by comparing the likelihood of this equation and the augmented model (2) which is:

$\operatorname{Prob}\left\{Y_{i}=1\right\}=\Phi\left(\beta_{1}+\beta_{2} X_{2 i}+\ldots+\beta_{k} X_{k i}+\beta_{1}^{\prime}+\beta_{2}^{\prime} D_{i} \times X_{2 i}+\ldots+\beta_{k}^{\prime} D_{i} \times X_{k i}\right)$

where $D_{\mathrm{i}}$ is the dummy variable for bank characteristics. We compute a LR statistic for the null of stability: $\mathrm{LR}=2\left[\log L_{2}-\log L_{1}\right]$. Under the null, LR is distributed as a $\chi^{2}(k)$.

13 As mentioned in section 1, we focus on the post-crisis period but we also compute our correlation measures for the period 1996-1999. The results are available from the authors on request.
} 


\subsection{Potential systemic risk measures}

Table 4 produces descriptive statistics for mean domestic and cross border market adjusted returns correlations for the whole set of banks and for each country specific set of banks: ${ }^{14}$

\section{Table 4 here}

Based on the domestic correlation estimates, we are able to distinguish two sets of countries, a relatively low domestic correlation category (Indonesia with an average correlation of 0.03 , Malaysia, 0.09, Philippines, 0.05 , Singapore, 0.08 , Hong Kong, 0.13 and a high domestic correlation category (Korea with an average correlation of 0.24 , Thailand, 0.20 and Taiwan 0.36 . Cross border correlations are on average much lower and do not exhibit significant differences among countries. ${ }^{15}$

On the basis of estimations performed following equations (7) and (8) we construct two binary variables DP_DOM_2 $2_{\mathrm{i}}$ and $\mathrm{DB} \_\mathrm{CB} \_2_{\mathrm{i}}$. Recall that $\mathrm{DP} \_D O M \_2_{\mathrm{i}}\left(\right.$ respectively $\left.\mathrm{DP} \_\mathrm{CB} \_2_{\mathrm{i}}\right)$ equals 1 if bank $i(P)$ overreacts or contributes to an increase in the domestic (respectively cross border) country $(P)$ mean correlations during periods for which this country domestic (respectively cross border) correlations are significant. Table 5 shows the country distribution of these binary dependent variables and their cross distribution. One can note from the cross distribution that banks which highly contribute to domestic correlations are, on the whole, different from banks highly contributing to cross border correlations.

Table 5 here

\footnotetext{
14 These descriptive statistics are calculated on the basis of the two dimensions: through time (2000 - 2005 period) and through individuals.

${ }^{15}$ We also apply the same method using Merton Distance to Default measures instead of market-adjusted returns (results available on request). In this case mean correlations are generally higher and the values are closer for the different countries in our sample except Singapore and the Philippines which exhibit much lower average values.
} 


\subsection{Results of Probit model}

Tables 6 and 7 sum up the results obtained on the basis of simple probit estimations. For each variable, we check for the robustness of the results with regard to the estimation sample by bootstrapping it one thousand times. Each bootstrapped sample is built on random draws within the actual sample. We require that at least 50 observations are available whatever the value of the explained variable and that, at least, 10 observations are available for the binary variable $Y=1$ at each step. At this preliminary stage we can notice that the variables that are most likely to increase individual bank $i(P)$ contribution to the average domestic correlation level of country $\mathrm{P}$ are balance sheet structure variables $\left(M 6_{-}\right.$NL_TA_DEP_TA, M6_ NL_TEA_DEP_TA, M6_ NL_TEA_CSTF_TA, M6_NL_TEA), liquidity variables (M6_NL_CSTF) and variables reflecting the extent of non banking activities (M6_ NOIT_AVAS). ${ }^{16}$ When explaining contribution to cross border correlations, the most significant variables are "asset quality" variables (M6_LLP_GL, M6_ LLP_TA, M6_LLR_IL), income structure variables (M6_NMARG) or market based risk indicators (M6_ BETA). These results suggest that in the case of cross-country correlations (cross border spillovers) market participants rely only on asset risk and default risk indicators computed on the basis of either accounting information (asset quality and capital adequacy) or market information (systematic risk). However, for domestic correlations (risk within the domestic banking system) such variables have no explanatory power. Market based indicators are never significant and only liquidity risk and bank opaqueness variables tend to increase the correlation of a bank's unexplained performance with those of other banks. In particular, asset opaqueness as measured by the share of non-tradable loans, the reliance on deposits or short term funding and the extent to which the bank relies on traditional intermediation activities (transformation of short term deposits into loans) as measured by the interactive variables M6_NL_TA_DEP_TA, M6_ NL_TEA_DEP_TA, M6_NL_TEA_CSTF_TA, play a significant role. The optimal multivariate 
probit models presented in Tables 8 (domestic correlations) and 9 (cross border correlations) confirm these findings. Because there is a presumption of high collinearity between the stepwise selected regressors, we produce two estimates: first, no a priori condition is required with regard to collinearity among the selected variables; second, a low level of collinearity is required as mentioned above. The regressors that were pre-selected and introduced in our optimal models are shown at the bottom of Tables 8 and 9 along with their correlation matrix.

\section{Tables 8 and 9 here}

In each case, we test further for the null of adequacy between theoretical and estimated probabilities by conducting the Hosmer Lemeshow goodness-of-fit-test ${ }^{17}$ (Tables 8-A and 9-A).

Tables 8-A and 9-A here

When we account for collinearity among the regressors, in both cases (domestic and cross border equations) the null of adequacy between estimated and theoretical probabilities is not rejected at the $5 \%$ risk level. The stability tests results ${ }^{18}$ are shown in Table 8-B (domestic correlations equation) and Table 9-B (cross border correlations equation).

Tables 8-B and 9-B here

${ }^{16}$ Non operating items $=$ Non Operating Incomes (net profit on value adjusted of financial assets, share in net income of equity accounted affiliates...) - Non Operating Expenses (write downs of goodwills...) Income Tax.

17 The Hosmer Lemeshow Test enables to test for the null of adequacy between theoretical and estimated probabilities of $Y_{i}=1$. To implement this test, one's has to group the $\mathrm{N}$ individuals of the sample in J groups on the basis of increasing estimated probabilities. Under the null, the HL statistic is distributed as a $\chi^{2}(J-2)$.

${ }^{18}$ We test for the stability of our last models through a LR test based on the comparison of the respective performances of two models:

Model 1: $Y_{i}=\alpha+\beta X_{i}+\gamma Z_{i}+\varepsilon_{I}$

Model M2: $Y_{i}=\alpha+\beta X_{i}+\gamma Z_{i}+\alpha^{\prime} D_{i}+\beta^{\prime} X_{i}^{*} D_{i}+\gamma^{\prime} Z_{i}{ }^{*} D_{i}+\varepsilon_{I}$

where $D_{i}$ is a dummy variable that enables us to account for the possible influence of the size of the bank (domestic or world ranking of assets), support of authorities, specialisation (commercial or investment bank), individual rating, country... (see Table 7 for $D_{i}$ definitions).

Under the null $\left(\mathrm{H}_{0}\right.$ : stability of coefficients $\left.\{\alpha, \beta, \gamma\}\right)$, the LR statistic is distributed as a $\chi(2 k)$ where $k$ is the number of estimated coefficients in model 1. 
On the whole one or three variables survive the stepwise process defined above to optimally predict significant correlations. Default risk variables accounting for risk exposure, profitability and the amount of equity that serves as a cushion against failure have been rejected from the optimal models (capital adequacy variables and Z scores). For domestic correlations (Table 8), the highest predictive power is obtained with the interactive variable capturing the extent of traditional intermediation activity M6_ NL_TEA_DEP_TA. Therefore, a higher proportion of deposits on the liability side of the balance sheet combined with a larger share of loans in total assets increases bank exposure or contribution to systemic risk (higher probability). For cross border correlations, when we account for collinearity among regressors, the highest predictive power is obtained with the market based systematic risk indicator (M6_BETA) and to a lesser extent with the ratios of loan loss reserves to impaired loans (M6_LLR_IL) and loan loss provisions to gross loans (M6_LLP_GL). Therefore, for cross border spillover effects that can be captured through the linkages between bank stock returns, market participants seem to rely more on market risk indicators such as the beta and to a lesser extent on bank asset risk (asset quality) as reflected by loan loss reserves or loan loss provisions. For cross border contagion the market does not seem to value liquidity risk, asset opaqueness and default risk (probability of failure). In contrast, at the domestic level, co-movements of market-adjusted returns are not driven by asset risk considerations but solely by illiquidity and asset opaqueness.

\section{Conclusion}

Previous studies on systemic risk in Southeast Asia focus on macroeconomic factors of bank contagion neglecting the information contained in bank stock prices. The aim of this paper is to propose a view based on a market model approach to assess the determinants of bank contagion at both the domestic and the cross border level in Southeast Asia. Our findings show that potential systemic risk measured as the correlation of the residuals of the market model significantly differs between two groups of countries. Indonesia, Malaysia, the Philippines, 
Singapore and Hong Kong, exhibit lower systemic risk than Korea, Thailand, and Taiwan. Our results also show that cross border contagion risk is better predicted by asset risk indicators whereas domestic contagion risk is better predicted by illiquidity and the extent of traditional intermediation activities (non tradable loans) which are opaque. Our findings suggest that whereas illiquidity, but not insolvency, is a major concern at the domestic level the opposite is true for cross-country contagion. 


\section{References}

Baig, T. and I. Goldfajn (1998), Financial market contagion in the Asian crisis, IMF working paper no. 98/155.

Boyd, J. and S. Graham (1986), Risk, regulation, and bank holding company expansion. Federal Reserve Bank of Mineapolis, Quaterly Review, spring.

Bystrom, H. (2004) The market's view on the probability of banking sector failure: cross-country comparisons, Journal of International Financial Markets, Institutions and Money 14, 419-438

Corsetti, G., Pericoli, M., and M. Sbracia (2005), Some contagion, some interdependence: More pitfalls in tests of financial contagion, Journal of International Money and Finance 24, 1177-1199.

De Bandt, O., and P. Hartmann (2000), Systemic risk: A survey, CEPR discussion paper 2634.

De Nicolo, G. and M. Kwast (2002), Systemic risk and financial consolidation. Are they related ? Journal of Banking and Finance 26, 861-880.

Demirgüç-Kunt A., Detragiache E., and P. Gupta (2006, forthcoming), Inside the crisis: An empirical analysis of banking systems in distress, Journal of International Money and Finance.

Engle, R., 2002. Dynamic conditional correlation: a simple class of multivariate GARCH. Journal of Business and Economic Statistics 17 (5), 425-446.

Forbes, K. and R. Rigobon (2002), No contagion, only interdependence: measuring stock market comovements, Journal of Finance 57 (5), 2223-2261.

Gropp, R. and G. Moermann (2004), Measurement of contagion in banks' equity prices, Journal of International Money and Finance 23(3), 405-459.

Gropp and Vesala (2005), Measuring bank contagion using market data, unpublished manuscript.

Gropp, R., Vesala, J., and G. Vulpes (2004), Market indicators, bank fragility, and indirect market discipline, FRBNY Economic Policy Review, 53-62.

Hohl, S., McGuire, P., and E. Remolona (2005), Cross-border banking in Asia: Basel 2 and other prudential issues, BIS working paper.

Kaminsky, G. and C. Reinhart (2000), On crisis, contagion and confusion, Journal of International Economics 51, 145-168.

Sbracia, M. and A. Zaghini (2001), Crisis and contagion: The role of the banking system, BIS paper no. 1.

Sbracia, M. and A. Zaghini (2003), The role of the banking system in the international transmission of shocks, The World Economy 26(5), 727-754.

Schoenmaker, D. (1996), Contagion risk in banking, LSE FMG discussion paper no 239.

Worthington, A., and H. Higgs (2004), Transmission of equity returns and volatility in Asian developed and emerging markets: A multivariate GARCH analysis, International Journal of Finance and Economics 9, 7180 . 
Table 1

Accounting and market based regressors in Probit Models

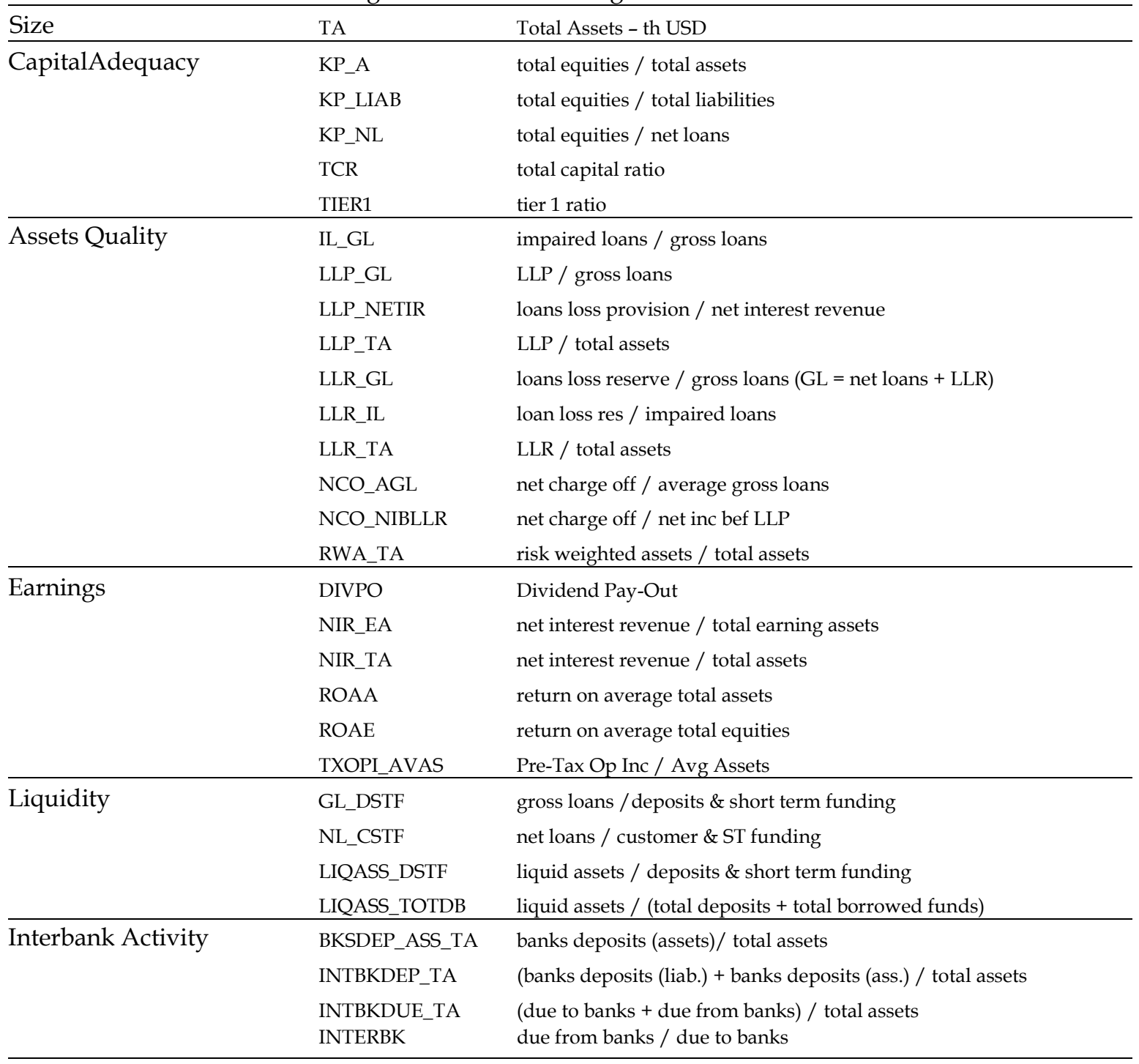


Table 1, Continued

Accounting and market based regressors in Probit Models

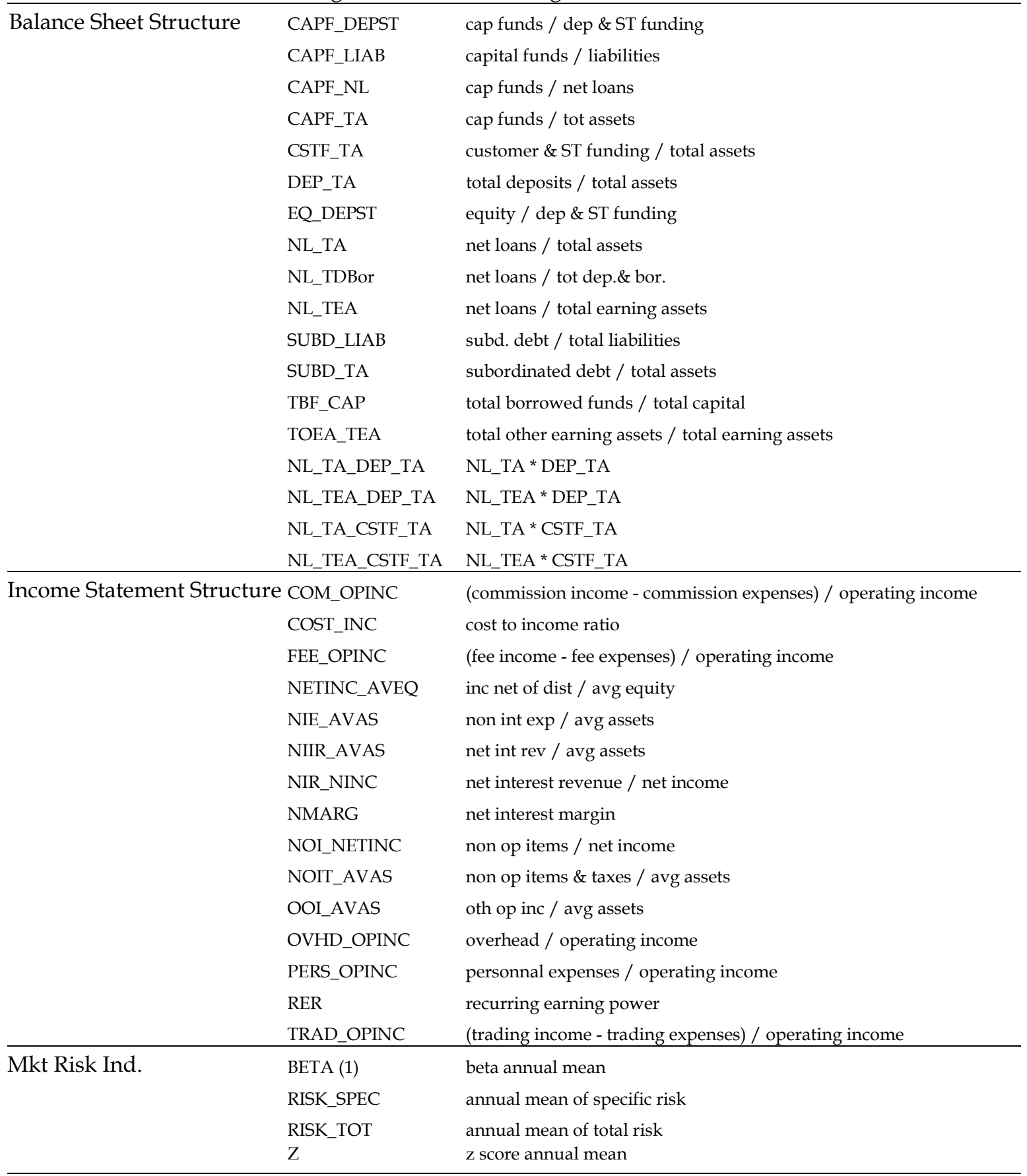


Table 2

Stability Test of the optimal equation: definition of dummy variables Dummy Equals one if (zero elsewhere):

D COM

Commercial bank

D_INV

Investment bank

D_HK

Nationality $=$ Hong Kong

D_ID

Nationality $=$ Indonesia

D_MY

Nationality $=$ Malaysia

D_SG

Nationality $=$ Singapore

D_PH

Nationality $=$ Philippines

D_TA

Nationality $=$ Taïwan

D_TH

Nationality $=$ Thailand

D_KO

D_CRK10

Nationality $=$ Korea

D_WRLDRK500

Country Rank $\leq 10$

World Rank $\leq 500$ 
Table 3

Statistical properties of the regressors

Observations that induced a standard deviation / sample mean ratio greater than two were ruled out

\begin{tabular}{|c|c|c|c|c|c|c|}
\hline & Mean & Median & Maximum & Minimum & Std. Dev. & Observations \\
\hline M6_TA 19 & 10906739 & 3980695 & 146000000 & 26386 & 20521751 & 123 \\
\hline M6_KP_A & 19.066 & 9.776 & 94.282 & 0.114 & 20.255 & 123 \\
\hline M6_KP_LIAB & 20.751 & 10.845 & 112.975 & 5.513 & 23.108 & 99 \\
\hline M6_KP_NL & 51.543 & 21.538 & 423.753 & 7.777 & 77.127 & 97 \\
\hline M6_TCR & 15.538 & 15.129 & 29.845 & 9.732 & 4.661 & 68 \\
\hline M6_TIER1 & 19.654 & 10.982 & 146.4 & 5.6 & 28.439 & 59 \\
\hline M6_IL_GL & 9.019 & 6.152 & 45.962 & -2.286 & 8.402 & 87 \\
\hline M6_LLP_GL & 1.411 & 1.217 & 13.699 & -2.522 & 1.846 & 95 \\
\hline M6_LLP_NETIR & 24.122 & 19.665 & 76.037 & -4.441 & 21.066 & 84 \\
\hline M6_LLP_TA & 0.745 & 0.546 & 4.887 & -0.841 & 0.86 & 106 \\
\hline M6_LLR_GL & 8.624 & 5.586 & 67.321 & 0.704 & 10.254 & 100 \\
\hline M6_LLR_IL & 70.334 & 69.512 & 339.004 & -475 & 87.907 & 86 \\
\hline M6_LLR_TA & 3.902 & 2.494 & 30.203 & 0.221 & 4.806 & 100 \\
\hline M6_NCO_AGL & 3.197 & 1.475 & 31.296 & -0.472 & 5.568 & 63 \\
\hline M6_NCO_NIBLLR & 59.025 & 51.682 & 212.062 & 5.033 & 50.572 & 41 \\
\hline M6_RWA_TA & 66.148 & 67.022 & 93.596 & 39.838 & 12.965 & 39 \\
\hline M6_DIVPO & 49.6 & 38.887 & 243.732 & -3.262 & 40.65 & 64 \\
\hline M6_NIR_EA & 2.716 & 2.581 & 5.325 & 1.33 & 1.027 & 95 \\
\hline M6_NIR_TA & 2.576 & 2.206 & 31.281 & -17.458 & 4.425 & 119 \\
\hline M6_ROAA & 0.965 & 0.966 & 3.074 & -0.863 & 0.868 & 98 \\
\hline M6_ROAE & 7.282 & 6.764 & 19.517 & -13.076 & 6.404 & 98 \\
\hline M6_TXOPI_AVAS & 1.036 & 0.984 & 3.013 & -0.866 & 0.977 & 74 \\
\hline M6_GL_DSTF & 72.749 & 73.002 & 130.347 & 39.058 & 17.942 & 77 \\
\hline M6_NL_CSTF ${ }^{20}$ & 59.315 & 63.426 & 96.096 & -1.385 & 23.056 & 100 \\
\hline M6_LIQASS_DSTF & 45.994 & 31.7 & 182.933 & 12.331 & 36.881 & 94 \\
\hline M6_LIQASS_TOTDB & 41.067 & 27.875 & 250.005 & 1.01 & 38.087 & 102 \\
\hline M6_BKSDEP_ASS_TA & 10.59 & 6.795 & 50.904 & 0.176 & 10.983 & 88 \\
\hline M6_INTBKDEP_TA & 13.961 & 9.384 & 66.885 & 2.463 & 12.523 & 71 \\
\hline M6_INTBKDUE_TA & 21.76 & 17.137 & 70.831 & 4.535 & 13.554 & 54 \\
\hline M6_INTERBK & 764.846 & 381.862 & 4099.456 & 119.634 & 918.808 & 36 \\
\hline M6_CAPF_DEPST & 20.019 & 12.64 & 111.278 & 6.553 & 19.735 & 77 \\
\hline M6_CAPF_LIAB & 39.202 & 11.487 & 429.675 & 1.809 & 75.742 & 99 \\
\hline M6_CAPF_NL & 30.06 & 20.604 & 193.189 & 8.475 & 29.51 & 76 \\
\hline M6_CAPF_TA & 19.21 & 10.355 & 94.283 & 0.114 & 20.3 & 100 \\
\hline M6_CSTF_TA & 75.433 & 81.843 & 92.229 & 5.206 & 18.19 & 93 \\
\hline M6_DEP_TA & 66.942 & 77.473 & 92.186 & 0.577 & 25.356 & 116 \\
\hline M6_EQ_DEPST & 24.997 & 11.856 & 228.18 & 5.904 & 35.443 & 92 \\
\hline M6_NL_TA & 46.364 & 48.284 & 94.147 & -0.458 & 22.23 & 121 \\
\hline
\end{tabular}

19 Thousand of US\$.

${ }^{20}$ For this variable, we have also ruled out 15 observations greater than $100 \%$. 


\begin{tabular}{lrrrrrr} 
M6_NL_TDBOR & 74.94 & 62.385 & 752.257 & -1.04 & 88.068 & 110 \\
M6_NL_TEA & 54.53 & 55.912 & 100 & -1.318 & 24.118 & 121 \\
M6_SUBD_LIAB & 3.677 & 2.488 & 26.041 & 0.028 & 4.785 & 67 \\
M6_SUBD_TA & 2.952 & 2.073 & 14.737 & 0.026 & 2.971 & 67 \\
M6_TBF_CAP & 60.836 & 43.481 & 243.21 & 0.016 & 64.047 & 37 \\
M6_TOEA_TEA & 46.605 & 45.253 & 101.318 & 0.2 & 24.52 & 122 \\
M6_NL_TA_DEP_TA & 3535.611 & 3743.405 & 6819.55 & 6.257 & 2042.047 & 114 \\
M6_NL_TEA_DEP_TA & 4046.926 & 4270.138 & 8229.203 & 18.607 & 2215.36 & 114 \\
M6_NL_TA_CSTF_TA & 3899.952 & 4116.232 & 6820.052 & -15.116 & 2006.485 & 93 \\
M6_NL_TEA_CSTF_TA & 4433.504 & 4504.436 & 8220.851 & -43.524 & 2147.106 & 93 \\
M6_COM_OPINC & 34.352 & 33.106 & 48.676 & 16.877 & 11.416 & 8 \\
M6_COST_INC & 70.639 & 60.131 & 419.444 & 24.965 & 46.054 & 117 \\
M6_FEE_OPINC & 75.671 & 57.841 & 307.005 & -75.927 & 82.376 & 48 \\
M6_NETINC_AVEQ & 6.47 & 5.092 & 18.715 & -3.064 & 5.382 & 59 \\
M6_NIE_AVAS & 5.783 & 3.611 & 31.297 & 0.704 & 6.398 & 120 \\
M6_NIIR_AVAS & 2.739 & 2.296 & 32.496 & -14.416 & 4.587 & 119 \\
M6_NIR_NINC & 266.806 & 191.474 & 960.165 & -2.545 & 216.566 & 95 \\
M6_NMARG & 2.805 & 2.687 & 5.211 & 0.938 & 1.052 & 95 \\
M6_NOI_NETINC & 10.594 & 6.097 & 45.783 & -17.236 & 15.448 & 73 \\
M6_NOIT_AVAS & -0.188 & -0.163 & 0.245 & -0.973 & 0.26 & 77 \\
M6_OOI_AVAS & 4.52 & 1.406 & 35.299 & -3.594 & 7.794 & 120 \\
M6_OVHD_OPINC & 202.433 & 155.63 & 620.328 & -55.5 & 148.892 & 96 \\
M6_PERS_OPINC & 92.57 & 69.097 & 238.904 & 6.672 & 59.864 & 84 \\
M6_RER & 2.016 & 1.567 & 15.915 & -18.447 & 3.735 & 122 \\
M6_TRAD_OPINC & 9.718 & 6.423 & 44.602 & -6.569 & 12.465 & 25 \\
M6_BETA & 0.971 & 0.957 & 2.038 & 0.11 & 0.374 & 124 \\
M6_RISK_SPEC & 0.055 & 0.051 & 0.167 & 0.018 & 0.024 & 124 \\
M6_RISK_TOT & 0.067 & 0.065 & 0.177 & 0.02 & 0.025 & 124 \\
M6_Z & 19.229 & 17.659 & 49.319 & 6.048 & 7.991 & 124 \\
\hline & & & & & & \\
& & & &
\end{tabular}


Table 4

Descriptive per country statistics for returns correlations

\begin{tabular}{|c|c|c|c|c|c|c|}
\hline \multicolumn{7}{|c|}{ Mean Individual Domestic Correlations; [2000 - 2005] Descriptive Statistics } \\
\hline Set of banks & Number of banks & Mean & StDev & Min & $\operatorname{Max}$ & Median \\
\hline Full Set & 125 & 0.184 & 0.167 & -0.354 & 0.717 & 0.167 \\
\hline Hong Kong & 12 & 0.132 & 0.121 & -0.232 & 0.520 & 0.123 \\
\hline Indonesia & 16 & 0.030 & 0.067 & -0.191 & 0.254 & 0.029 \\
\hline Korea & 20 & 0.242 & 0.156 & -0.147 & 0.717 & 0.228 \\
\hline Malaysia & 9 & 0.091 & 0.116 & -0.354 & 0.372 & 0.087 \\
\hline Philippines & 13 & 0.055 & 0.089 & -0.176 & 0.353 & 0.045 \\
\hline Singapore & 4 & 0.079 & 0.127 & -0.240 & 0.373 & 0.086 \\
\hline Taiwan & 22 & 0.361 & 0.142 & -0.186 & 0.687 & 0.376 \\
\hline Thailand & 29 & 0.203 & 0.126 & -0.289 & 0.516 & 0.208 \\
\hline \multicolumn{7}{|c|}{ Mean Individual Cross Border Correlations; [2000 - 2005] Descriptive Statistics } \\
\hline Set of banks & Number of banks & Mean & StDev & Min & $\operatorname{Max}$ & Median \\
\hline Full Set & 125 & 0.005 & 0.037 & -0.155 & 0.163 & 0.005 \\
\hline Hong Kong & 12 & 0.002 & 0.041 & -0.136 & 0.132 & 0.003 \\
\hline Indonesia & 16 & 0.000 & 0.040 & -0.155 & 0.117 & 0.000 \\
\hline Korea & 20 & 0.009 & 0.037 & -0.116 & 0.163 & 0.008 \\
\hline Malaysia & 9 & 0.012 & 0.040 & -0.104 & 0.135 & 0.013 \\
\hline Philippines & 13 & 0.006 & 0.035 & -0.121 & 0.141 & 0.005 \\
\hline Singapore & 4 & 0.014 & 0.035 & -0.066 & 0.130 & 0.015 \\
\hline Taiwan & 22 & 0.003 & 0.032 & -0.118 & 0.121 & 0.003 \\
\hline Thailand & 29 & 0.001 & 0.038 & -0.135 & 0.130 & 0.002 \\
\hline
\end{tabular}


Table 5

Distribution of the binary variables DP_DOM_2_and et DP_CB_2 (returns based correlations) Set of Banks Nb of Banks DP_DOM Tot. Obs. DP_DOM $=1$ DP_CB Nb Tot. Obs. DP_CB $=1$

\begin{tabular}{lrrrrr}
\hline Full Set & 125 & 117 & 40 & 113 & 36 \\
Hong Kong & 12 & 12 & 5 & 12 & 3 \\
Indonesia & 16 & 14 & 2 & 13 & 5 \\
Korea & 20 & 20 & 7 & 20 & 5 \\
Malaysia & 9 & 9 & 3 & 9 & 3 \\
Philippines & 13 & 11 & 4 & 11 & 1 \\
Singapore & 4 & 4 & 1 & 4 & 0 \\
Taïwan & 22 & 21 & 7 & 20 & 7 \\
Thailand & 29 & 26 & 11 & 24 & 12 \\
\hline
\end{tabular}

\begin{tabular}{l|llll} 
Cross distribution & \multicolumn{4}{c}{ DP_CB_2 } \\
\hline Count & \multicolumn{3}{c}{ Total } \\
DP_DOM_2 & 0 & 50 & 23 & 73 \\
& 1 & 27 & 13 & 40 \\
& Total & 77 & 36 & 113 \\
\hline
\end{tabular}


Table 6

Simple Model*: DP DOM 2 (returns based correlations)

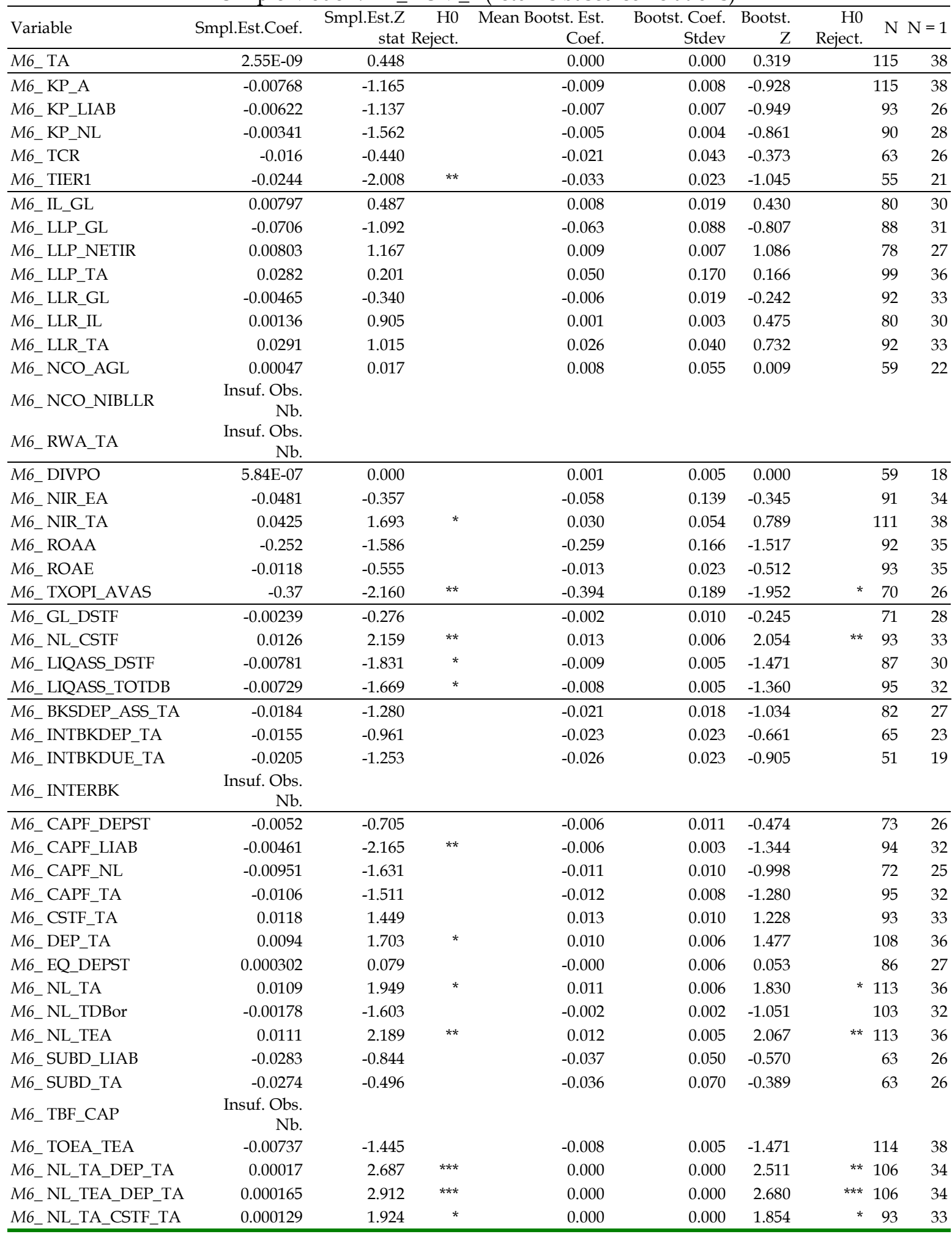


Table 6

Simple Model*: DP_DOM_2 (returns based correlations)

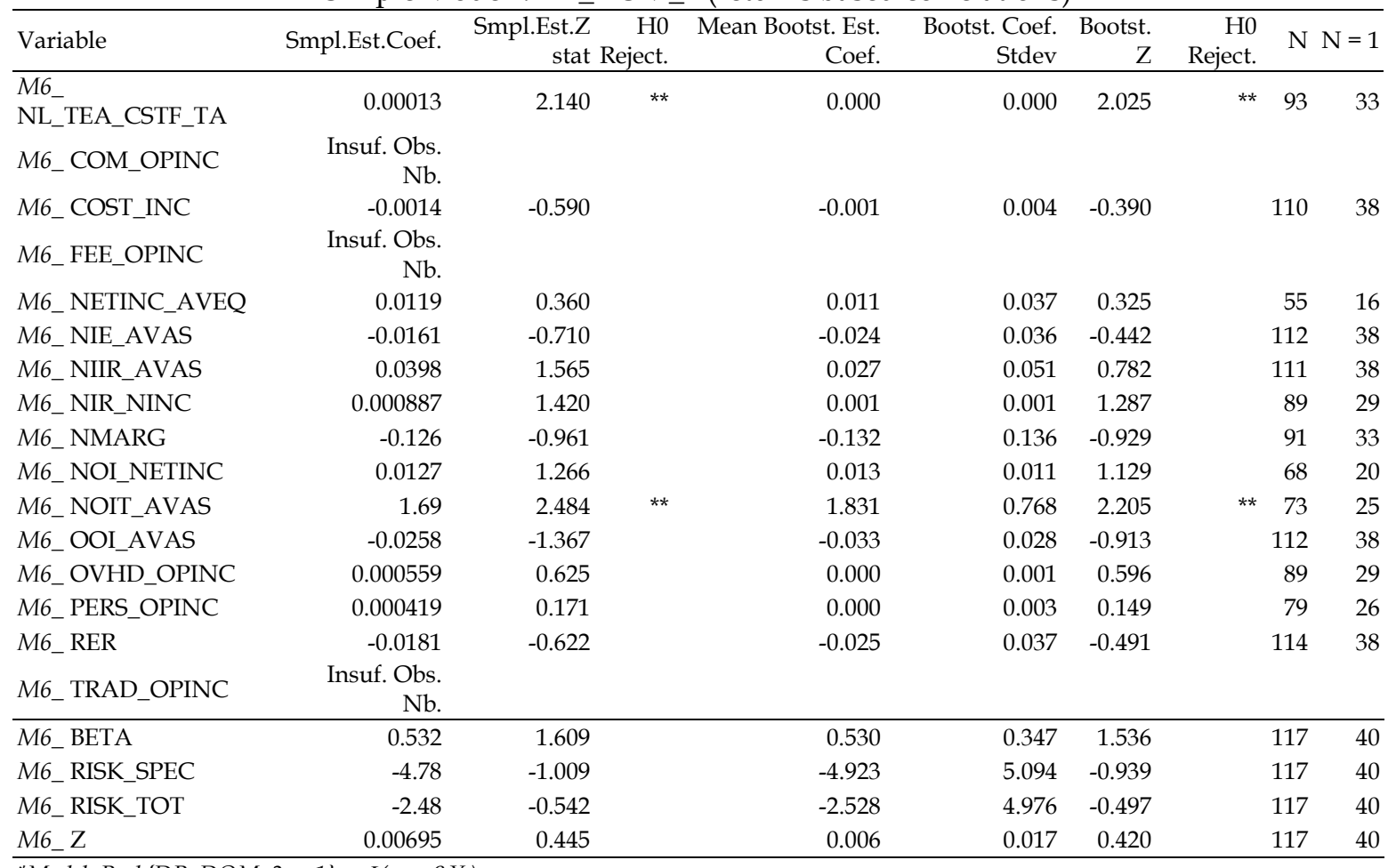

*Model: Prob $\left\{D P \_D O M \_2_{i}=1\right\}=\Phi\left(\alpha+\beta X_{i}\right)$

$\Phi($.$) is the cumulated frequency function of the Normal distribution$

$D P \_D O M \_2_{i}=1$ if coefficient $\lambda_{i}$ in equation $/ 7 /$ is significantly greater than 1 (risk level for the test $=2 \%$ )

Method: ML - Binary Probit (Newton-Raphson) - QML (Huber/White) standard errors \& covariance

We required at least 50 observations and 10 observations such that the explained variable equals one.

Bootstrapped coefficients and standard deviation are based on 1000 bootstrapping replications. 
Table 7: Simple Model: DP_CB_2 (returns based correlations)

\begin{tabular}{|c|c|c|c|c|c|c|c|}
\hline \multirow[b]{2}{*}{ Variable } & \multicolumn{2}{|c|}{ Smpl.Est. } & \multicolumn{2}{|c|}{ Mean Bootst. Bootst. Coef. } & & & \\
\hline & Smpl.Est.Coef. & Z stat H0 Reject & t Est. Coef. & Stdev & Bootst. Z H0 Reject. & $\mathrm{N}$ & $\mathrm{N}=1$ \\
\hline M6_TA & $-4.13 \mathrm{E}-09$ & -0.693 & 0 & 0.000 & -0.427 & 111 & 35 \\
\hline M6_KP_A & 0.00107 & 0.181 & 0.001 & 0.007 & 0.161 & 111 & 35 \\
\hline M6_KP_LIAB & 0.00123 & 0.192 & 0.001 & 0.008 & 0.148 & 89 & 28 \\
\hline M6_KP_NL & 0.00366 & 1.950 & 0.004 & 0.002 & 1.485 & 86 & 30 \\
\hline M6_TCR & -0.0108 & -0.35 & -0.009 & 0.034 & -0.316 & 63 & 17 \\
\hline M6_TIER1 & 0.011 & 1.696 & 0.021 & 0.026 & 0.418 & 54 & 20 \\
\hline M6_IL_GL & 0.00785 & 0.470 & 0.008 & 0.019 & 0.406 & 80 & 28 \\
\hline M6_LLP_GL & -0.413 & -2.522 & -0.457 & 0.186 & -2.228 & 87 & 29 \\
\hline M6_LLP_NETIR & -0.00135 & -0.184 & -0.001 & 0.008 & -0.175 & 75 & 27 \\
\hline M6_LLP_TA & -0.633 & -2.677 & -0.684 & 0.246 & -2.572 & 96 & 31 \\
\hline M6_LLR_GL & 0.0131 & 0.899 & 0.018 & 0.019 & 0.698 & 91 & 29 \\
\hline M6_LLR_IL & 0.00632 & 2.419 & 0.007 & 0.003 & 2.101 & 80 & 28 \\
\hline M6_LLR_TA & 0.0614 & 1.855 & 0.071 & 0.047 & 1.298 & 91 & 29 \\
\hline M6_NCO_AGL & 0.0297 & 0.958 & 0.040 & 0.053 & 0.564 & 59 & 18 \\
\hline M6_NCO_NIBLLR & Insuf. Obs. Nb. & & & & & & \\
\hline M6_RWA_TA & Insuf. Obs. Nb. & & & & & & \\
\hline M6_DIVPO & -0.00749 & -1.448 & -0.009 & 0.006 & -1.158 & 59 & 13 \\
\hline M6_NIR_EA & -0.246 & -1.641 & -0.263 & 0.165 & -1.488 & 89 & 30 \\
\hline M6_NIR_TA & -0.0281 & -0.854 & -0.058 & 0.080 & -0.35 & 108 & 35 \\
\hline M6_ROAA & 0.0449 & 0.267 & 0.047 & 0.182 & 0.247 & 89 & 30 \\
\hline M6_ROAE & 0.00704 & 0.320 & 0.009 & 0.024 & 0.294 & 90 & 31 \\
\hline M6_TXOPI_AVAS & 0.0747 & 0.461 & 0.081 & 0.174 & 0.429 & 68 & 24 \\
\hline M6_GL_DSTF & 0.00426 & 0.443 & 0.004 & 0.010 & 0.412 & 71 & 22 \\
\hline M6_NL_CSTF & 0.00467 & 0.768 & 0.005 & 0.007 & 0.711 & 91 & 27 \\
\hline M6_LIQASS_DSTF & -0.00163 & -0.415 & -0.002 & 0.004 & -0.368 & 85 & 27 \\
\hline M6_LIQASS_TOTDB & 0.00157 & 0.467 & 0.001 & 0.004 & 0.372 & 93 & 30 \\
\hline M6_BKSDEP_ASS_TA & -0.00996 & -0.748 & -0.011 & 0.014 & -0.688 & 82 & 25 \\
\hline M6_INTBKDEP_TA & 0.00566 & 0.459 & 0.005 & 0.015 & 0.376 & 65 & 22 \\
\hline M6_INTBKDUE_TA & 0.00101 & 0.070 & -0.002 & 0.018 & 0.055 & 51 & 14 \\
\hline M6_INTERBK & Insuf. Obs. Nb. & & & & & & \\
\hline M6_CAPF_DEPST & 0.00366 & 0.493 & 0.004 & 0.010 & 0.372 & 72 & 25 \\
\hline M6_CAPF_LIAB & 0.000441 & 0.257 & 0.000 & 0.002 & 0.182 & 93 & 29 \\
\hline M6_CAPF_NL & 0.00383 & 0.734 & 0.005 & 0.008 & 0.509 & 71 & 25 \\
\hline M6_CAPF_TA & -0.000651 & -0.102 & -0.001 & 0.007 & -0.091 & 94 & 29 \\
\hline
\end{tabular}


Table 7: Simple Model*: DP_CB_2 (returns based correlations)

\begin{tabular}{|c|c|c|c|c|c|c|c|}
\hline Variable & Smpl.Est.Coef. & Smpl.Est. H0 Reject & $\begin{array}{l}\text { ean Bootst. } \\
\text { Est. Coef. }\end{array}$ & $\begin{array}{r}\text { Bootst. Coef. } \\
\text { Stdev } \\
\end{array}$ & Bootst. Z H0 Reject. & $\mathrm{N}$ & $\mathrm{N}=1$ \\
\hline M6_CSTF_TA & 0.00559 & 0.784 & 0.006 & 0.008 & 0.688 & 91 & 27 \\
\hline M6_DEP_TA & -0.000197 & -0.038 & 0 & 0.006 & -0.034 & 104 & 32 \\
\hline M6_EQ_DEPST & -0.00277 & -0.732 & -0.003 & 0.006 & -0.432 & 83 & 24 \\
\hline M6_NL_TA & 0.00239 & 0.437 & 0.002 & 0.006 & 0.410 & 109 & 35 \\
\hline M6_NL_TDBor & 0.000241 & 0.181 & 0.001 & 0.003 & 0.087 & 100 & 33 \\
\hline M6_NL_TEA & 0.00264 & 0.525 & 0.003 & 0.005 & 0.524 & 109 & 35 \\
\hline M6_SUBD_LIAB & 0.0105 & 0.326 & 0.009 & 0.055 & 0.191 & 63 & 24 \\
\hline M6_SUBD_TA & -0.00162 & -0.031 & 0.003 & 0.067 & -0.024 & 63 & 24 \\
\hline M6_TBF_CAP & Insuf. Obs. Nb. & & & & & & \\
\hline M6_TOEA_TEA & -0.0027 & -0.56 & -0.003 & 0.005 & -0.524 & 110 & 34 \\
\hline M6_NL_TA_DEP_TA & $-1.19 \mathrm{E}-05$ & -0.187 & 0 & 0.000 & -0.177 & 102 & 32 \\
\hline M6_NL_TEA_DEP_TA & $-5.65 \mathrm{E}-06$ & -0.095 & 0 & 0.000 & -0.089 & 102 & 32 \\
\hline M6_NL_TA_CSTF_TA & 3.94E-05 & 0.568 & 0.000 & 0.000 & 0.518 & 91 & 27 \\
\hline M6_NL_TEA_CSTF_TA & 4.47E-05 & 0.691 & 0.000 & 0.000 & 0.668 & 91 & 27 \\
\hline M6_COM_OPINC & Insuf. Obs. Nb. & & & & & & \\
\hline M6_COST_INC & -0.00153 & -0.637 & -0.001 & 0.004 & -0.403 & 107 & 34 \\
\hline M6_FEE_OPINC & Insuf. Obs. Nb. & & & & & & \\
\hline M6_NETINC_AVEQ & 0.0244 & 0.664 & 0.025 & 0.039 & 0.625 & 55 & 9 \\
\hline M6_NIE_AVAS & -0.0103 & -0.481 & -0.014 & 0.027 & -0.378 & 108 & 35 \\
\hline M6_NIIR_AVAS & -0.0336 & -0.966 & -0.052 & 0.073 & -0.459 & 108 & 35 \\
\hline M6_NIR_NINC & -0.00128 & -1.954 & -0.001 & 0.001 & -1.738 & 86 & 29 \\
\hline M6_NMARG & -0.342 & -2.361 & -0.354 & 0.154 & -2.218 & 89 & 29 \\
\hline M6_NOI_NETINC & 0.0083 & 0.794 & 0.008 & 0.012 & 0.715 & 66 & 24 \\
\hline M6_NOIT_AVAS & 0.0154 & 0.025 & 0.023 & 0.692 & 0.022 & 71 & 24 \\
\hline M6_OOI_AVAS & 0.0129 & 0.843 & 0.013 & 0.017 & 0.751 & 108 & 35 \\
\hline M6_OVHD_OPINC & -0.000501 & -0.573 & 0 & 0.001 & -0.552 & 86 & 29 \\
\hline M6_PERS_OPINC & -0.00144 & -0.637 & -0.001 & 0.002 & -0.593 & 76 & 26 \\
\hline M6_RER & 0.0659 & 1.832 & 0.070 & 0.044 & 1.500 & 110 & 35 \\
\hline M6_TRAD_OPINC & Insuf. Obs. Nb. & & & & & & \\
\hline M6_BETA & 0.715 & 2.038 & 0.736 & 0.359 & 1.995 & 113 & 36 \\
\hline M6_RISK_SPEC & 4.32 & 0.863 & 5.255 & 5.726 & 0.754 & 113 & 36 \\
\hline M6_RISK_TOT & 5.89 & 1.207 & 6.326 & 5.253 & 1.122 & 113 & 36 \\
\hline M6_Z & -0.0224 & -1.219 & -0.026 & 0.020 & -1.095 & 113 & 36 \\
\hline
\end{tabular}

${ }^{*}$ Model: Prob $\left\{D P \_C B \_22_{i}=1\right\}=\Phi\left(\alpha+\beta X_{i}\right) ; \Phi($.$) is the cumulated frequency function of the Normal distribution$

$D P \_C B \_2{ }_{i}=1$ if coefficient $\lambda_{i}^{\prime}$ in equation $/ 8 /$ is significantly greater than 1 (risk level for the test $=2 \%$ )

Method: ML - Binary Probit (Newton-Raphson) - QML (Huber/White) standard errors $\mathcal{E}$ covariance

We required at least 50 observations and 10 observations such that the explained variable equals one.

Bootstrapped coefficients and standard deviation are based on 1000 bootstrapping replications. 
Table 8

Optimal Multivariate Model for Domestic Contributions (returns based correlations)

\begin{tabular}{|c|c|c|c|c|}
\hline \multicolumn{5}{|c|}{ Dependent Variable: DP_DOM_2 } \\
\hline Variable & Coefficient & Std. Error & z-Statistic & Prob. \\
\hline M6_NL_TEA_DEP_TA & $0.000165^{\star *}$ & 5.65E-05 & 2.911642 & 0.0036 \\
\hline $\mathrm{C}$ & $-1.173837^{* * *}$ & 0.269240 & -4.359815 & 0.0000 \\
\hline LR statistic (1 df) & 7.191470 & \multicolumn{2}{|c|}{ McFadden R-squared } & 0.054064 \\
\hline Probability(LR stat) & 0.007325 & & & \multirow{3}{*}{106} \\
\hline Obs with Dep $=0$ & 72 & \multirow{2}{*}{\multicolumn{2}{|c|}{ Total obs }} & \\
\hline Obs with Dep=1 & 34 & & & \\
\hline
\end{tabular}

Model: $D P \_D O M \_2_{i}=\Phi\left(\alpha+\beta_{l} X_{1 i}+\ldots+\beta_{k} X_{k i}\right)$

$\Phi($.$) is the cumulated frequency function of the Normal distribution$

$D P \_D O M \_2_{i}=1$ if coefficient $\lambda_{i}$ in equation $/ 7 /$ is significantly greater than 1 (risk level for the test $=2 \%$ )

Method: ML - Binary Probit (Newton-Raphson) - QML (Huber/White) standard errors $\mathcal{E}$ covariance

We required at least 50 observations and 10 observations such that the explained variable equals one.

***** and * indicate significance respectively at the $1 \%, 5 \%$ and $10 \%$ levels.

9 regressors were pre-selected : M6_TXOPI_AVAS, M6_NL_CSTF, M6_NL_TA, M6_NL_TEA, M6_NOIT_AVAS, M6_

NL_TA_CSTF_TA, M6_NL_TA_DEP_TA, M6_NL_TEA_CSTF_TA, M6_NL_TEA_DEP_TA. Because the selection process

yields only one regressor, collinearity is not a concern.

Correlations matrix of pre-selected regressors

M6_TXOPI_AVAS

M6_NL_CSTF

M6_NL_TA

M6 NL TEA

M6_NOIT_AVAS

M6_NL_TA_CSTF_TA

M6_NL_TA_DEP_TA

M6_NL_TEA_CSTF_TA -0.56

M6_NL_TEA_DEP_TA $\mid-0.58$

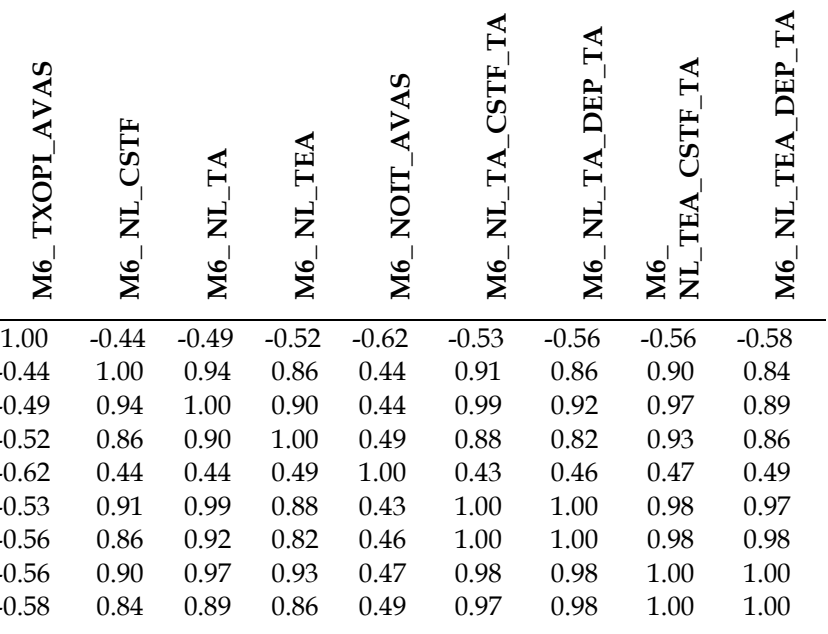


Table 9

Optimal Multivariate Model for Cross Border Contributions (returns based correlations)

No a priori collinearity restriction

\begin{tabular}{|c|c|c|c|c|}
\hline \multicolumn{5}{|c|}{ Dependent Variable: DP_CB_2 } \\
\hline Variable & Coefficient & Std. Error & z-Statistic & Prob. \\
\hline M6_LLR_IL & 0.009257 & 0.004301 & 2.152453 & 0.0314 \\
\hline M6_BETA & 1.261574 & 0.534145 & 2.361857 & 0.0182 \\
\hline M6_NMARG & -0.373183 & 0.166449 & -2.242030 & 0.0250 \\
\hline $\mathrm{C}$ & -1.253237 & 0.809196 & -1.548743 & 0.1214 \\
\hline LR statistic (3 df) & \multicolumn{2}{|c|}{ 13.78436 McFadden R-squared } & & 0.144988 \\
\hline Probability(LR stat) & \multicolumn{2}{|c|}{0.003214 Total obs } & & 73 \\
\hline Obs with Dep $=0$ & \multicolumn{2}{|c|}{47 Farrar Glauber Stat } & & 6.34 \\
\hline Obs with Dep $=1$ & \multicolumn{3}{|c|}{26 Farrar PVal for rejection } & $38.54 \%$ \\
\hline \multicolumn{5}{|c|}{ A priori collinearity restriction ${ }^{21}$} \\
\hline \multicolumn{5}{|c|}{ Dependent Variable: DP_CB_2 } \\
\hline Variable & Coefficient & Std. Error & z-Statistic & Prob. \\
\hline M6_LLR_IL & $0.007309^{* *}$ & 0.003228 & 2.264309 & 0.0236 \\
\hline M6_BETA & $1.670992^{* * *}$ & 0.476487 & 3.506899 & 0.0005 \\
\hline M6_LLP_GL & $-0.382435^{* *}$ & 0.185744 & -2.058938 & 0.0395 \\
\hline $\mathrm{C}$ & $-2.129443^{* * *}$ & 0.601612 & -3.539563 & 0.0004 \\
\hline LR statistic (3 df) & 21.93437 & McFadden R-squared & & 0.237225 \\
\hline Probability(LR stat) & $6.73 \mathrm{E}-05$ & Total obs & & 73 \\
\hline Obs with Dep $=0$ & 49 & Farrar Glauber Stat & & 2.36 \\
\hline Obs with Dep $=1$ & 241 & Farrar PVal for rejection & & $88.35 \%$ \\
\hline
\end{tabular}

Model: $D P \_C B \_2{ }_{i}=\Phi\left(\alpha+\beta_{l} X_{1 i}+\ldots+\beta_{k} X_{k i}\right)$

$\Phi($.$) is the cumulated frequency function of the Normal distribution$

$D P \_C B \_2{ }_{i}=1$ if coefficient $\lambda_{1}^{\prime}{ }_{i}$ in equation $/ 8 /$ is significantly greater than 1 (risk level for the test $=2 \%$ )

Method: ML - Binary Probit (Newton-Raphson) - QML (Huber/White) standard errors $\mathcal{E}$ covariance

We required at least 50 observations and 10 observations such that the explained variable equals one.

$* * * * *$ and $*$ indicate significance respectively at the $1 \%, 5 \%$ and $10 \%$ levels.

6 regressors were pre-selected: M6_LLP_GL, M6_LLP_TA, M6_LLR_IL, M6_NIR_NINC, M6_NMARG, M6_BETA.

Correlations matrix of pre-selected variables

\begin{tabular}{|l|l|l|l|l|l|l|}
\hline & M6_LLP_GL & M6_LLP_TA & M6_LLR_IL & M6_NIR_NINC & M6_NMARG & M6_BETA \\
\hline M6_LLP_GL & 1.00 & 0.61 & 0.06 & 0.21 & 0.11 & 0.10 \\
\hline M6_LLP_TA & 0.61 & 1.00 & -0.05 & 0.13 & -0.03 & 0.04 \\
\hline M6_LLR_IL & 0.06 & -0.05 & 1.00 & -0.03 & 0.11 & -0.09 \\
\hline M6_NIR_NINC & 0.21 & 0.13 & -0.03 & 1.00 & 0.30 & -0.22 \\
\hline M6_NMARG & 0.11 & -0.03 & 0.11 & 0.30 & 1.00 & -0.15 \\
\hline M6_BETA & 0.10 & 0.04 & -0.09 & -0.22 & -0.15 & 1.00 \\
\hline
\end{tabular}

Table 8 A

Goodness of Fit Test (Hosmer Lemeshow) for the Table 8 equation.

21 To that purpose we render the introduction of a variable impossible if its introduction would induce a rejection of the null (no collinearity) with a p-value less than $50 \%$. 


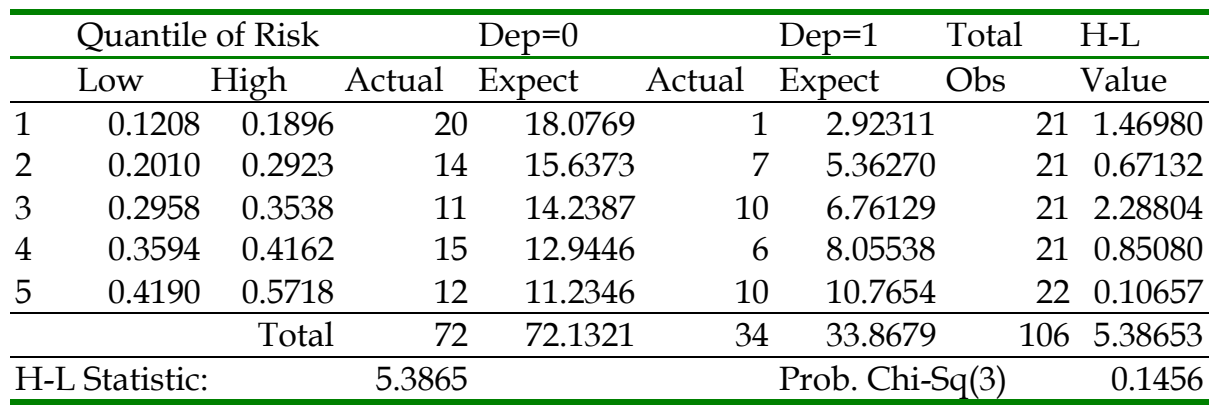

The null of adequacy between theoretical and estimated probabilities cannot be rejected for a risk level less than $14.5 \%$.

Table 9 A

Goodness of Fit Test (Hosmer Lemeshow) for the Table 9 equation.

No a priori collinearity restriction

\begin{tabular}{rrrrrrrrr}
\hline & \multicolumn{3}{c}{ Quantile of Risk } & \multicolumn{2}{c}{ Dep $=0$} & Dep $=1$ & Total & H-L \\
\hline & Low & High & Actual & Expect & Actual & Expect & Obs & Value \\
\hline 1 & 3.E-08 & 0.1903 & 11 & 12.7574 & 3 & 1.24262 & 14 & 2.72747 \\
2 & 0.1998 & 0.2795 & 12 & 11.3086 & 3 & 3.69135 & 15 & 0.17175 \\
3 & 0.2891 & 0.4053 & 12 & 9.24862 & 2 & 4.75138 & 14 & 2.41175 \\
4 & 0.4075 & 0.5013 & 5 & 8.18649 & 10 & 6.81351 & 15 & 2.73053 \\
5 & 0.5054 & 0.9135 & 7 & 5.37202 & 8 & 9.62798 & 15 & 0.76863 \\
\hline \multicolumn{3}{c}{ Total } & 47 & 46.8732 & 26 & 26.1268 & 73 & 8.81012 \\
\hline \multicolumn{7}{l}{ H-L Statistic: } & 8.8101 & \multicolumn{5}{c}{ Prob. Chi-Sq(3) } & 0.0319 \\
\hline
\end{tabular}

The null of adequacy between theoretical and estimated probabilities cannot be rejected for a risk level less than $3.2 \%$.

A priori collinearity restriction

\begin{tabular}{rrrrrrrrr}
\hline & \multicolumn{3}{c}{ Quantile of Risk } & \multicolumn{2}{c}{ Dep $=0$} & Dep=1 & Total & H-L \\
\hline & Low & High & Actual & Expect & Actual & Expect & Obs & Value \\
\hline 1 & 0.0002 & 0.1054 & 13 & 13.1702 & 1 & 0.82975 & 14 & 0.03713 \\
2 & 0.1154 & 0.2156 & 11 & 12.5634 & 4 & 2.43656 & 15 & 1.19775 \\
3 & 0.2228 & 0.3065 & 12 & 10.3064 & 2 & 3.69356 & 14 & 1.05481 \\
4 & 0.3179 & 0.4999 & 10 & 8.74135 & 5 & 6.25865 & 15 & 0.43435 \\
5 & 0.5005 & 0.9597 & 3 & 4.11073 & 12 & 10.8893 & 15 & 0.41342 \\
\hline & & Total & 49 & 48.8922 & 24 & 24.1078 & 73 & 3.13746 \\
\hline H-L Statistic: & & 3.1375 & \multicolumn{5}{c}{ Prob. Chi-Sq(3) } & 0.3709 \\
\hline
\end{tabular}

The null of adequacy between theoretical and estimated probabilities cannot be rejected for a risk level less than $37.1 \%$. 
Table 8-B

Stability test for optimal stepwise selected equation of DP_DOM_2 $\operatorname{Prob}\left\{D P \_D O M \_2=1\right\}=\Phi\left(\beta_{1}+\beta_{2} M \sigma_{-} N L_{-} T E A \_D E P \_T A\right)$

\begin{tabular}{lrrrr}
\hline Dummy & LR Stat N.Obs & $\begin{array}{r}\text { N.Obs } \\
1\end{array}$ & $\begin{array}{r}\text { PVal for } \\
\text { rej. }\end{array}$ \\
\hline d_crk10 & 2.71 & 98 & 31 & 25.85 \\
d_wrldrk500 & 1.73 & 95 & 30 & 42.11 \\
d_com & 1.35 & 104 & 33 & 51.03 \\
d_inv & 5.02 & 104 & 33 & 8.14 \\
dum_id & 1.14 & 106 & 34 & 56.47 \\
dum_hk & 0.69 & 106 & 34 & 70.78 \\
dum_ko & 0.82 & 106 & 34 & 66.33 \\
dum_my & 0.27 & 106 & 34 & 87.34 \\
dum_ph & 0.55 & 106 & 34 & 75.78 \\
dum_sg & 5.50 & 106 & 34 & 6.40 \\
dum_ta & 2.50 & 106 & 34 & 28.60 \\
dum_th & 0.92 & 106 & 34 & 63.04 \\
\hline
\end{tabular}

The null of stability cannot be rejected for a 5\% risk level

We compare the likelihoods of the stepwise selected equation and the augmented model:

Stepwise Selected Model 1: Prob $\left\{D P \_D O M \_2_{i}=1\right\}=\Phi\left(X_{i} \beta\right)$

Augmented model 2: Prob $\left\{D P \_D O M \_2_{i}=1\right\}=\Phi\left(X_{i} \beta, X_{i} \times D_{i} \times \beta^{\prime}\right)$ where $D_{i}$ is a dummy variable defined hereafter $\left(X=M 6 \_N L \_T E A \_D E P \_T A\right)$

We compute a $L R$ statistic for the null of stability: $L R=2\left[\log L_{2}-\log L_{1}\right]$. Under the null, $L R$ is

distributed as a $\chi^{2}(2)$. 
Table 9-B

Stability test for optimal stepwise selected equation of DP_CB_2

\begin{tabular}{lrrrr} 
Prob $\left\{D P \_V B \_2=1\right\}=\Phi\left(\beta_{1}+\beta_{2} M 6 \_L L R \_I L+\beta_{3} M 6 \_B E T A+\beta_{4} M\right.$ \\
\hline Dummy & LR Stat & N.Obs & N.Obs 1 & PVal for rej. \\
\hline d_crk10 & 1.02 & 69 & 26 & 90.61 \\
d_wrldrk500 & 7.08 & 66 & 25 & 13.18 \\
d_com & 1.89 & 72 & 28 & 75.58 \\
d_inv & 1.24 & 72 & 28 & 87.22 \\
dum_id & 10.93 & 73 & 28 & $2.73 * *$ \\
dum_hk & 2.29 & 73 & 28 & 68.26 \\
dum_ko & - & - & - & - \\
dum_my & - & - & - & - \\
dum_ph & 1.92 & 73 & 28 & 75.09 \\
dum_sg & - & - & - & - \\
dum_ta & 5.98 & 73 & 28 & 20.04 \\
dum_th & 3.52 & 73 & 28 & 47.43 \\
\hline \multirow{2}{*}{$* *$ indicate significance at the $5 \%$ level } &
\end{tabular}

We compare the likelihoods of the stepwise selected equation and the augmented model: Stepwise Selected Model 1:Prob $\left\{D P \_C B \_2{ }_{i}=1\right\}=\Phi\left(X_{i} \beta\right)$

Augmented model 2: Prob $\left\{D P \_C B \_2_{i}=1\right\}=\Phi\left(X_{i} \beta, X_{i} \times D_{i} \times \beta^{\prime}\right)$ where $D_{i}$ is a dummy variable defined hereafter (X = M6_LLR_IL, M6_BETA, M6_LLP_GL)

We compute a $L R$ statistic for the null of stability: $L R=2\left[\log L_{2}-\log L_{1}\right]$. Under the null, $L R$ is distributed as a $\chi^{2}(2)$. 